\title{
Free-Stall Dimensions: Effects on Preference and Stall Usage
}

\author{
C. B. Tucker, D. M. Weary, and D. Fraser \\ Animal Welfare Program, \\ Faculty of Agricultural Sciences, \\ University of British Columbia, \\ Vancouver, Canada V6N 1 Z4
}

\section{ABSTRACT}

In 2 experiments, free-stall dimensions were examined to determine how they affected stall preference, usage, cleanliness, and milk production in Holstein dairy cattle. In experiment 1, stall width (112 or 132 $\mathrm{cm}$ ) and stall length (229 and $274 \mathrm{~cm}$ from curb to wall) were compared in a $2 \times 2$ factorial arrangement of stall treatments using 15 individually housed, non-lactating animals. Cows showed no clear preference for stall size as measured by lying time. When animals had no choice between stalls, average lying time was higher in the wide stalls than in the narrow stalls (10.8 vs. $9.6 \pm$ $0.3 \mathrm{~h} / 24 \mathrm{~h}$ ). Both length and width affected time spent standing with only the front hooves in the stall; total stall area is best explained by the variation associated with this behavior. In experiment 2, 27 lactating dairy cattle were alternately housed with access to stalls of 106,116 , or $126 \mathrm{~cm}$ in width using a cross-over design with exposure to each treatment lasting $3 \mathrm{wk}$. Animals spent an additional $42 \mathrm{~min} / 24 \mathrm{~h}$ lying in stalls measuring $126 \mathrm{~cm}$ in width compared with stalls with only 106 $\mathrm{cm}$ between partitions. Free-stall width influenced the time spent standing with the front 2 hooves in the stall; animals averaged $58 \mathrm{~min} / 24 \mathrm{~h}$ in the widest stalls and $85 \mathrm{~min} / 24 \mathrm{~h}$ in the narrowest stalls. The amount of time spent standing with all 4 hooves in the stall tended to be longer in wider stalls, and these stalls were also most likely to become soiled with feces. Stall width did not affect the number of lying events or milk production. In conclusion, animals spent more time lying down, and less time was spent standing with only the front hooves in larger stalls, but larger stalls were also more likely to become soiled.

(Key words: dairy cattle, behavior, free-stall, housing)

Received August 19, 2003.

Accepted December 19, 2003.

Corresponding author: C. Tucker; e-mail: cassandra.tucker@agresearch.co.nz.

\section{INTRODUCTION}

Dairy producers are faced with a range of recommendations concerning suitable dimensions for free-stalls. For example, recommendations for overall stall bed length range from 200 to $274 \mathrm{~cm}$, and recommendations for space for a lateral head lunge range between 40 and $60 \mathrm{~cm}$ (Faull et al., 1996; Bickert, 2000). Recommendations for stall width are generally given in terms of the size of the animals. Common recommendations are about twice the hip width, which often translates into approximately 100 to $120 \mathrm{~cm}$ (Irish and Martin, 1983; McFarland and Gamroth, 1994; Bickert, 2000). Little is known about the range of stall sizes found on farms in North America, but a recent survey of 37 farms in the UK found that $87 \%$ of stalls measured were $<230$ $\mathrm{cm}$ in length and 50\% were between 115 and $122 \mathrm{~cm}$ in width (Faull et al., 1996). The variation in recommendations reflects the lack of adequate results on freestall dimensions and their effects on cow behavior.

Indeed, what is known about the space requirements for dairy cattle comes from the literature examining the standing up and lying down movements (Lidfors, 1989). The lunge space, or the space taken up by the head of the animal as it moves forward to stand up, is often thought of as the optimal length requirement. However, until recently, there were few reliable estimates of the space requirements for dairy cattle. One exception is the results of kinematic analysis of the standing up movements, which indicate that dairy cattle use between 260 and $280 \mathrm{~cm}$ of total longitudinal space (from the nose to the most caudal point of the cow), and that lateral displacements during this movement range from 60 to $110 \mathrm{~cm}$ at the hips (Ceballos, 2003). Estimates of space used by the head while lunging, based on the longitudinal movement of the nose, range between 22 and $76 \mathrm{~cm}$ (Ceballos, 2003).

The size of the lying area may affect the behavior of dairy cattle. Comparisons of the results of Haley et al. (2000, 2001) suggest that lying times were 1.5 to $2 \mathrm{~h}$ lower in tie stalls $\left(180 \times 130 \mathrm{~cm}\right.$ or $2.3 \mathrm{~m}^{2}$ per cow per mattress surface) than in larger pens $(420 \times 390 \mathrm{~cm}$ or $16.4 \mathrm{~m}^{2}$ per cow per mattresses surface). In addition, 
in one study, heifers were housed in straw-bedded pens with $1.8,2.7$, or $3.6 \mathrm{~m}^{2}$ of lying space (Mogensen et al., 1997), and in another, cows were housed with either 9 or $4.5 \mathrm{~m}^{2}$ of bedded area per cow (Fregonesi and Leaver, 2002). In both experiments, the animals showed no differences in lying time associated with space allowance. These previous studies can provide some insight into the effect, or lack of effect, of the size of the lying area. However, they are inadequate as a basis for recommendations for free-stall design, as neither of those studies examined how animals interact with the free-stall infrastructure without constraints such as tethers.

The objective of the 2 experiments described in this paper was to assess the impact of free-stall size on dairy cattle behavior, specifically stall usage and preference. Preference testing, or allowing an animal to choose between alternative housing designs, can provide insights into aspects of housing design that may be important to the cow. Results from preference tests can correspond with the behavioral response to an option when the animal has no choice. Time spent in the stall, particularly lying down, is an important response variable because it can provide information about how comfortable animals find a given stall design (Tucker et al., 2003). Together, the combination of information about changes in stall usage and preferences can provide a more comprehensive evaluation of which housing features affect cattle. The first experiment evaluated how the width and the forward lunge space of free-stalls affected cow preference and stall usage. The second experiment also examined the effect of free-stall width on stall usage and assessed other considerations such as milk production and stall cleanliness. The dimensions tested in both experiments represented the range seen in the industry.

\section{MATERIALS AND METHODS}

\section{Experiment 1: Free-stall Width and Forward Lunge Space}

Fifteen Holstein cows, all in the last 8 wk of pregnancy, were used as subjects (average weight \pm SD: 720 $\pm 69 \mathrm{~kg}$; average parity $\pm \mathrm{SD}: 3.73 \pm 1.58$ ). Before this experiment, the subjects had been housed in a freestall barn where stalls measured $116 \mathrm{~cm}$ between stall partitions and either 229 or $274 \mathrm{~cm}$ in length. During this study, each animal was housed alone in a test pen containing a row of 4 free-stalls. In each stall, the neck rail was positioned $125 \mathrm{~cm}$ above the geotextile mattress base and $160 \mathrm{~cm}$ from the curb. A $10-\mathrm{cm}$ high plastic brisket pillow was positioned $165 \mathrm{~cm}$ from the curb (Figure 1). Stalls were bedded with 2 to $3 \mathrm{~cm}$ of sawdust and were cleaned each day during the morning

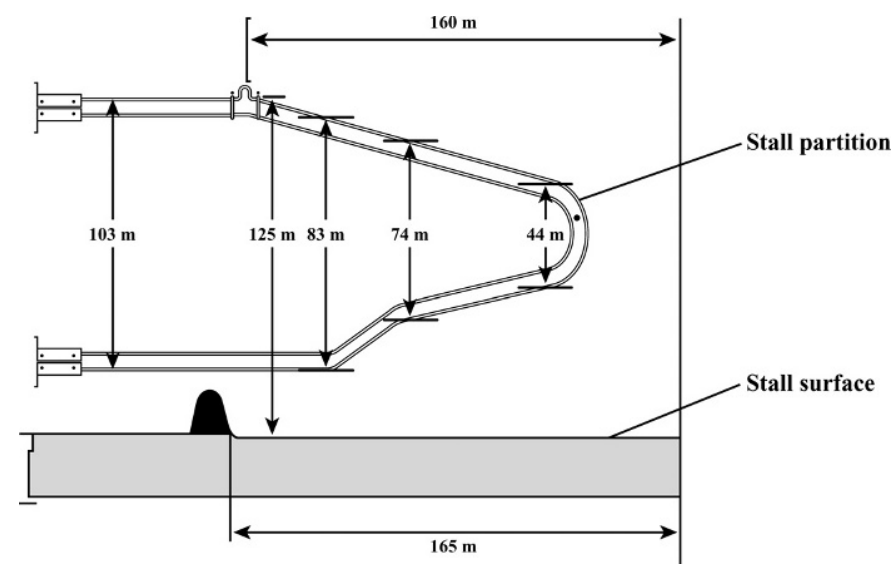

Figure 1. Design of free-stall partition used in experiments 1 and 2 .

and afternoon feedings (0800 and $1500 \mathrm{~h}$ ). The animals were fed grass hay ad libitum.

Trios of animals were tested simultaneously in the 3 identical test pens at the South Campus Large Animal Research Facility, located in Vancouver, British Columbia, during the summer and fall of 1999. During the experiment, each animal was housed alone in a test pen containing a feed trough, a waterer, and 4 freestalls accessible from the alley. All flooring outside the freestall area was concrete. The 4 free-stalls in each pen varied in width and length according to a $2 \times 2$ arrangement of treatments. Stall length (short $[\mathrm{S}]=$ $229 \mathrm{~cm}$; long $[\mathrm{L}]=274 \mathrm{~cm}$ ) was altered by adjusting the lunge space available in front of the brisket board, as this is often the space eliminated in smaller stalls in commercial conditions. Stall width (narrow $[\mathrm{N}]=112$ $\mathrm{cm}$; wide $[\mathrm{W}]=132 \mathrm{~cm}$ ) was altered by adjusting the space between stall partitions. The 4 stalls thus varied in total area available from $2.48 \mathrm{~m}^{2}$ to $3.51 \mathrm{~m}^{2}$. For each animal, a combination of treatments (e.g., WL, NS, WS, NL) was assigned randomly to the 4 positions in a pen.

Each test consisted of 3 consecutive phases: adjustment, restriction, and free choice. During the adjustment phase, animals had free access to all 4 stalls for $7 \mathrm{~d}$, which allowed animals to settle into the facilities, as they were normally housed at a different location. During the restriction phase, animals were allowed access to only a single stall at a time, each for a 2-d period, with the order of access assigned randomly. In a preliminary experiment in our facility we found that restricting animals for $2 \mathrm{~d}$ yielded the same behavioral results (e.g., lying time) as a 10-d period of restriction. The restriction phase ensured that animals had shortterm experience with each option before testing preferences and allowed us to measure stall usage. During 
the free-choice phase, animals were again allowed free access to all 4 stalls for $2 \mathrm{~d}$. Again, the length of freechoice phase was based on preliminary results, which indicated that preferences for free-stall features, such as bedding, are reasonably stable over time. Thus, the final $24 \mathrm{~h}$ of a 2 -d period provided a representative sample of this information.

Each animal was video recorded during the last 24$\mathrm{h}$ period of the adjustment, restriction, and free-choice phases for a total of $6 \mathrm{~d}$ of recording. Recordings were at 3 frames/s using a Panasonic AG-6720 time-lapse VCR, a Panasonic WJ-FS 10 digital-frame switcher, and a Panasonic WV-BP330 CCTV camera. Cameras were located with a full view of all 4 stalls, and $100-\mathrm{W}$ white light was hung between 3 and $6 \mathrm{~m}$ above each set of stalls to facilitate recording at night. Video tapes were watched continuously, and the following behaviors were recorded: 1) lying in the stall, 2) standing with 4 hooves in the stall, 3) standing with the front 2 hooves in the stall, and 4) the number of lying events. Lying down outside the stall was not recorded and was rarely seen in live observations of the animals. Mean lying bout duration was calculated by dividing total lying time by the number of lying events in each $24-\mathrm{h}$ period. Because of technical malfunction, preference data (free-choice phase) were recorded for only 12 of the 15 animals.

Statistical analyses. Analysis of preferences was based on lying time, as this behavior provides a clear indicator that the animals are willing to use the stall. Specifically, lying time was used to rank each option to assess which option a given animal preferred. The probability of a given number of animals choosing either the wide or long stalls was compared using a binomial test. For the preference information, the interaction between width and lunge space was compared using the Fisher's exact test. In addition, as the animals did not spend all of their time in one stall, a value was calculated representing the composite size of the freestalls used during this phase (proportion of lying time in the stall multiplied by the area of that stall). The relationship between this variable (composite size of free-stall used during preference phase) and animal weight was tested using Pearson correlation.

A general linear model was used to analyze differences in the dependent variables during the restriction phase. This model included a term for animals (14 df), terms for order of exposure to treatments ( $3 \mathrm{df}$ ), width ( $1 \mathrm{df})$, length ( $1 \mathrm{df})$, and the width by length interaction (1 df), which were tested against the residual error term (39 df). For behaviors where the analysis showed effects of both width and length, a similar model was used to test the linear, quadratic, and cubic effect of total stall area $(1 \mathrm{df}$ each). The higher order effects (quadratic and cubic) were never significant and are not reported further. Both the correlation and the general linear model were carried out using SAS (1989).

\section{Experiment 2: Free-stall Width}

One objective of this experiment was to re-assess the effect of stall width on stall usage, as the results from experiment 1 indicated that this was an important factor influencing lying time. However, in this experiment we tested lactating cattle managed under commercial conditions and, thus, could also assess how stall width affected milk production and stall cleanliness. We used 27 Holstein cattle divided into 3 groups of 9, balanced for lactation number (mean \pm SD: $3.30 \pm 1.63$ ) and DIM (mean \pm SD: $71.5 \pm 20.5$ ). Each group of 9 animals was housed in one of 3 pens, each with 9 stalls at the University of British Columbia's Dairy Education and Research Centre in Agassiz, British Columbia during September, October, and November 2000. In a given pen, the 9 stalls were configured in 3 rows. Two rows faced one another, were open at the front (head-tohead), and had a total bed length of $240 \mathrm{~cm}$. The back row of stalls faced a cement wall, so these stalls were $30 \mathrm{~cm}$ longer to allow more space for the cow to lunge forward when getting up and lying down. All stalls measured $165 \mathrm{~cm}$ between the brisket board and the curb. Stalls were bedded with $40 \mathrm{~cm}$ of washed river sand. Animals were fed a total mixed ration and were milked twice a day at approximately 0600 and $1600 \mathrm{~h}$. All flooring outside the free-stall area was grooved concrete.

Free-stall partitions (Figure 1) were adjusted to give 3 stall widths of 106,116 , and $126 \mathrm{~cm}$, all measured as the space between the partitions. All stalls within a pen were adjusted to the same width for a 3 -wk period and then switched, such that treatments were assigned according to a Latin square design so that each width was tested once in each of the 3 periods, and once in each of the 3 pens.

The animals were videotaped using one video camera (Panasonic WV-BP330) per pen, a time-lapse videocassette recorder (Panasonic AG-6540), and a video multiplexer (Panasonic WJ-FS 216). To facilitate recording during the dark period, we suspended 2 red lights (100 $\mathrm{W},<5 \mathrm{~lx}$ ) approximately $8 \mathrm{~m}$ over each pen (same height as cameras). Observations began after the evening milking on Saturday and ended immediately before the evening milking on Sunday on the 1st and 3rd wk of each treatment. Observations were suspended while animals were absent from the pens during milking, which ranged from 29 to $170 \mathrm{~min} / 24 \mathrm{~h}$. Video tapes were watched continuously, and the following behaviors were recorded: 1) lying in the stall, 2) standing 
Table 1. Response measures (mean and SE) for cows in experiment $1(n=15)$ shown in relation to stall length and width during the restriction phase.

\begin{tabular}{|c|c|c|c|c|c|c|c|}
\hline & \multicolumn{3}{|c|}{ Width } & \multicolumn{3}{|c|}{ Length } & \multirow[b]{2}{*}{ SE } \\
\hline & $112 \mathrm{~cm}$ & $132 \mathrm{~cm}$ & $P$ & $229 \mathrm{~cm}$ & $274 \mathrm{~cm}$ & $P$ & \\
\hline \multicolumn{8}{|l|}{ Lying behavior } \\
\hline Lying events, no./24 h & 8.4 & 8.1 & 0.58 & 8.0 & 8.6 & 0.19 & 0.37 \\
\hline Duration of lying bouts, $h$ per bout & 1.3 & 1.5 & 0.01 & 1.4 & 1.4 & 0.79 & 0.05 \\
\hline Lying time, $\mathrm{h} / 24 \mathrm{~h}$ & 9.6 & 10.8 & 0.01 & 9.9 & 10.5 & 0.16 & 0.29 \\
\hline \multicolumn{8}{|l|}{ Standing behavior } \\
\hline Front hooves in stall, $\mathrm{min} / 24 \mathrm{~h}$ & 168 & 136 & 0.07 & 173 & 131 & 0.02 & 12.6 \\
\hline Four hooves in stall, $\mathrm{min} / 24 \mathrm{~h}$ & 106 & 93 & 0.38 & 91 & 108 & 0.22 & 10.2 \\
\hline Total standing in stall, $\min / 24 \mathrm{~h}$ & 275 & 228 & 0.04 & 264 & 239 & 0.26 & 15.2 \\
\hline
\end{tabular}

with 4 hooves in the stall, 3) standing with the front 2 hooves in the stall, and 4) the number of lying events. Individual animals were identified with markings made with Clairol's Nice and Easy \#122, Natural Black, or Clairol's L'image Maxiblonde, depending on hair color on the back.

Stall cleanliness and milk production. Fecal matter from each pen was collected and weighed during the Saturday morning, Saturday afternoon, and Sunday morning milkings of wk 1 and 3 of each treatment. We attempted to minimize the amount of sand mixed in with the fecal material, but the weights reported likely overestimate the amount of fecal material because of the bedding still present in the samples. After removing feces from each stall, the stall surface was leveled with a rake, in accordance with normal farm practice. Milk production was recorded at each milking and averaged across each 3 -wk treatment period.

Statistical analyses. To test the effect of stall width, these data were analyzed as a change-over experiment as described by Morris (1999). The individual animal served as the observational unit, as each animal was tested under each condition. Observations from wk 1 and 3 on each treatment were averaged for each cow. A general linear model was used to analyze differences in time spent lying, standing with 2 or 4 hooves in the stall, number of lying events, mean duration of lying bouts (lying time divided by number of lying events), and milk production. This model included a term for cows ( $26 \mathrm{df}$ ) and an order of exposure to each treatment ( $2 \mathrm{df})$ and tested the linear and quadratic effects of total stall width (1 df each) against the residual error (52 df). The quadratic effect was never statistically significant and is not reported further. For the analysis of stall cleanliness, pens served as the experimental unit because fecal material could not be identified based on individual animals. Fecal weights were log-transformed before analysis (because of unequal variances), and differences in stall cleanliness were analyzed using a general linear model that included a term for pen $(2$ df) and an order of exposure to each treatment ( $2 \mathrm{df}$ ) and tested the linear and quadratic effects of stall width ( $1 \mathrm{df}$ each) against the residual error ( $2 \mathrm{df}$ ).

\section{RESULTS}

\section{Experiment 1: Free-stall Width and Forward Lunge Space}

During the restriction phase, animals spent more time lying in the wide stalls than in the narrow stalls $(P=0.01$; Table 1$)$, but forward lunge space did not affect lying times $(P=0.16)$. The longer lying times can be explained by longer average lying bouts in wide stalls $(P=0.01)$. Both lunge space and width influenced the amount of time spent standing with the front hooves in the stall. As a result, this behavior was better explained by comparing the different stalls on the basis of total area available. Time spent standing with the

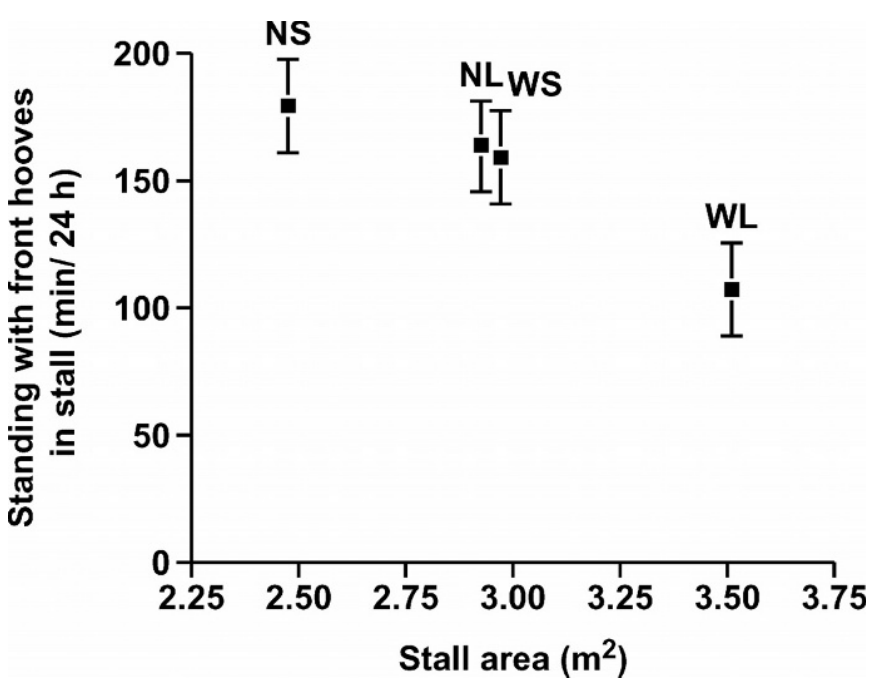

Figure 2. Mean time spent standing with the front 2 hooves in the stall $(\mathrm{min} / 24 \mathrm{~h} \pm \mathrm{SE})$ are shown in relation to total stall area $\left(\mathrm{m}^{2}\right)$ in each of the 4 stalls in experiment $1(\mathrm{n}=15)$. Each stall is labeled as its designation in the $2 \times 2$ arrangement of treatments (e.g., NS indicates narrow-short or $112 \times 229 \mathrm{~cm}$, and WL indicates wide-long or $132 \times 274 \mathrm{~cm}$ ). 
Table 2. Duration of lying (h per $24 \mathrm{~h}$ ) for the 4 stall sizes during the free-choice phase, shown for 12 individual animals in experiment 1 , together with weight $(\mathrm{kg})$ and composite size of the free-stall (calculated by summing the proportion of time spent lying in a given stall multiplied by the area of that stall).

\begin{tabular}{lllllll}
\hline & & \multicolumn{3}{c}{ Stall size } \\
\cline { 5 - 7 } Animal & BW & $\begin{array}{l}\text { Composite } \\
\text { stall size }\end{array}$ & $\begin{array}{c}\text { Narrow-short } \\
(112 \times 229 \mathrm{~cm})\end{array}$ & $\begin{array}{c}\text { Narrow-long } \\
(112 \times 274 \mathrm{~cm})\end{array}$ & $\begin{array}{c}\text { Wide-short } \\
(132 \times 229 \mathrm{~cm})\end{array}$ & $\begin{array}{c}\text { Wide-long } \\
(132 \times 274 \mathrm{~cm})\end{array}$ \\
\hline & $(\mathrm{kg})$ & $\left(\mathrm{m}^{2}\right)$ & & & & \\
1 & 760 & 3.05 & 1.8 & $4.0^{*}$ & 0.0 & 3.3 \\
2 & 608 & 2.77 & $4.3^{*}$ & 2.8 & 4.3 & 0.0 \\
3 & 734 & 3.35 & 0.0 & 0.0 & 4.2 & $10.0^{*}$ \\
4 & 758 & 3.07 & 0.0 & 0.0 & $6.5^{*}$ & 1.4 \\
5 & 742 & 2.95 & 0.5 & 0.0 & $9.8^{*}$ & 0.0 \\
6 & 766 & 2.97 & 0.0 & 0.0 & $12.7^{*}$ & 0.0 \\
7 & 618 & 2.81 & 4.1 & 0.0 & $6.8^{*}$ & 0.4 \\
8 & 630 & 2.97 & 0.0 & 0.0 & $12.5^{*}$ & 0.0 \\
9 & 624 & 2.90 & 1.6 & $11.1^{*}$ & 6.0 & 0.0 \\
10 & 799 & 2.94 & 0.5 & 2.7 & $10.5^{*}$ & 0.0 \\
11 & 743 & 2.89 & 0.7 & $7.7^{*}$ & 0.0 & 0.0 \\
12 & 686 & 3.20 & 0.0 & 5.7 & 1.4 & $5.9^{*}$ \\
Median & 738 & 2.96 & 0.5 & 1.4 & 6.2 & 0.0 \\
\hline
\end{tabular}

*Indicates stall size ranked first, based on lying time.

front 2 hooves in the stall was influenced by the total area of the stall $(P<0.01 ;$ Figure 2$)$. Standing with all 4 hooves in the stall and the number of lying events did not vary in relation to stall width or amount of forward lunge space $(P>0.1)$. Total time spent standing (with either 2 or 4 hooves in the stall) was higher in the narrow stalls $(P=0.04)$. There were no significant interactions between width and forward lunge space for any measure.

There was no consistent preference for lying in stalls of a given size: 6 cows ranked the wide-short stall as their first choice, 2 chose wide-long, 3 chose narrowlong, and one chose narrow-short (Table 2). Eight of 12 animals choose wide stalls $(P=0.19)$, and 7 of 12 animals chose stalls with more forward lunge space $(P=$ $0.39)$. There was no interaction between width and lunge space $(P=0.22)$. The amount of time cows spent lying on their first choice ranged from 38 to $100 \%$. There was no clear relationship between the weight of the animal and composite size of free-stalls used in the preference phase $(\mathrm{r}=0.40 ; P=0.20)$, although the two lightest animals did prefer to lie in smaller stalls (Animals 2 and 7 in Table 2).

\section{Experiment 2: Free-stall Width}

The linear effect of stall width was statistically significant for the total lying time and the duration of lying bouts $(P<0.05$; Table 3$)$. There was no effect of stall width on the number of lying events, total time spent standing in the stall, or milk production $(P>0.3)$. Time spent standing with the front 2 hooves in the stall was reduced with increasing stall width; the least amount of time (58 min) was spent in stalls measuring $126 \mathrm{~cm}$, and the most (85 min) was spent in stalls measuring $106 \mathrm{~cm}(P=0.01)$. The amount of time spent standing with all 4 hooves in the stall tended to increase with stall width, with the most standing taking place in the

Table 3. Lying and standing behavior and milk production (mean and SE; $P$ values for linear term) for 3 stall widths in experiment $2(\mathrm{n}=27)$.

\begin{tabular}{|c|c|c|c|c|c|}
\hline & \multicolumn{3}{|c|}{ Stall width } & \multirow[b]{2}{*}{$\mathrm{SE}$} & \multirow[b]{2}{*}{$P$} \\
\hline & $106 \mathrm{~cm}$ & $116 \mathrm{~cm}$ & $126 \mathrm{~cm}$ & & \\
\hline \multicolumn{6}{|l|}{ Lying behavior } \\
\hline Lying events, no./24 h & 12.3 & 11.9 & 11.9 & 0.38 & 0.45 \\
\hline Duration of lying bouts, $\mathrm{h}$ per bout & 1.1 & 1.2 & 1.2 & 0.03 & 0.04 \\
\hline Lying time, $\mathrm{h} / 24 \mathrm{~h}$ & 12.3 & 13.0 & 13.0 & 0.21 & 0.02 \\
\hline \multicolumn{6}{|l|}{ Standing behavior } \\
\hline Front hooves in stall, $\mathrm{min} / 24 \mathrm{~h}$ & 85 & 66 & 58 & 7.0 & 0.01 \\
\hline Four hooves in stall, $\min / 24 \mathrm{~h}$ & 53 & 50 & 68 & 5.8 & 0.06 \\
\hline Total standing in stall, $\min / 24 \mathrm{~h}$ & 138 & 116 & 126 & 8.0 & 0.33 \\
\hline \multicolumn{6}{|l|}{ Milk production } \\
\hline Amount of milk, kg/24 h & 47.0 & 45.8 & 46.2 & 0.77 & 0.62 \\
\hline
\end{tabular}


stall measuring $126 \mathrm{~cm} \mathrm{(68} \mathrm{min} ; P=0.06)$. There was also a linear, positive relationship between stall width and amount of fecal material in the pen (back-transformed means and $95 \%$ confidence intervals for weight of fecal material, $\mathrm{kg}$ per pen/24 h: $22.5+10.0 /-6.93,33.3$ $+11.3 /-8.4,53.9+36.9 /-21.9$, for stalls measuring 106 , 116 and $126 \mathrm{~cm}$, respectively, $\mathrm{n}=3, P=0.04$ ).

\section{DISCUSSION}

In both experiments, the animals spent more time lying down and had longer lying bouts in wider stalls, at least within the range tested in experiments 1 and 2. In experiment 2, lying times in stalls measuring 106 $\mathrm{cm}$ averaged $0.7 \mathrm{~h}$ less than in stalls measuring 116 or $126 \mathrm{~cm}$. In experiment 1 , the difference between lying times in stalls measuring 112 and $132 \mathrm{~cm}$ was $1.2 \mathrm{~h}$. These results are consistent with the limited research available on the effect of stall size on behavior. Wander (1976) reported decreased lying times in smaller stalls (although it is unclear how the stalls were smaller); also, narrow tie stalls $(1 \mathrm{~m})$ were found to reduce lying time compared with stalls of 1.1 and $1.2 \mathrm{~m}$ in width (Maton et al., 1978). However, animals differed in the magnitude of the response between experiments in the current study (Experiment 1: $1.2 \mathrm{~h}$; Experiment 2: 0.7 $\mathrm{h}$ ) and in their average lying time between the 2 experiments (experiment 1: $10.2 \mathrm{~h}$; experiment 2: $12.8 \mathrm{~h}$ ). These differences might have been due to differences in free-stall widths tested, to differences between the 2 groups of animals including stage of lactation or parturition, or to the environmental conditions under which the experiments were carried out (i.e., different facilities, management, etc.). Despite the difference in the magnitude of the responses, in both experiments the animals spent more total time lying down and exhibited longer lying bouts when using wider stalls.

The difference in the duration of lying bouts was not accompanied by a difference in the number of lying events. Other authors have hypothesized that a reduced number of lying events is associated with discomfort during rising and lying down (Haley et al., 2001); for example, more lying events were observed in stalls with softer surfaces that allow the knees to sink into the flooring material (Dumelow, 1995). These results suggest that the range of free-stall widths tested did not affect the decision to lie down.

One possible explanation for the longer lying bouts in wider stalls is that cows are less likely to contact the stall partitions in these stalls. Blom et al. (1984) placed pressure sensors on various parts of the free-stall and found that cows contact stall partitions over 100 times/ $\mathrm{d}$, but it was unclear whether the contact occurs while the animals were in a recumbent position or during the rising and lying movements. However, given that the frequency of lying events is well below 100, it seems likely that some of the contact with the stall partitions was occurring while lying in the stall. Haley et al. (2000) found that cows spent more time lying down when housed in large pens with mattress flooring compared with concrete tie stalls, but this difference was driven by a greater number of lying events rather than a change in the average duration of lying bouts as reported in the current study. However, the width of the tie stall in the Haley et al. (2000) experiment was 130 $\mathrm{cm}$, a value close to the upper range of those tested in experiments 1 and 2 , and the pen tested had no equivalent to free-stall partitions. Perhaps contact with the partitions only influences the duration of lying bouts at smaller widths.

The amount of forward lunge space in the free-stalls did not affect lying time, the length of lying bouts, or the number of lying events, despite the fact that the 229-cm treatments were at least $30 \mathrm{~cm}$ less than the 260 to $280 \mathrm{~cm}$ used by dairy cattle when rising (Ceballos, 2003). Perhaps a larger sample size would improve the chances of detecting a difference between the 2 treatments. However, it seems likely that amount of space required while resting would be less than the 260 to $280 \mathrm{~cm}$ used when lunging forward. Therefore, if lying time were to differ between treatments, this change would likely be mediated by a change in the number of lying events, as this is the movement most likely to be affected by restricted lunge space. Future work should evaluate the effects of lunge space on the difficulty of lying down and standing up.

Interestingly, when given a choice among free-stalls with different dimensions, cattle showed no clear preferences for lying in certain stalls, although there was a trend for animals to choose stalls of intermediate size (wide-short and narrow-long). This result differs from the clear and consistent preferences cattle show for free-stall lying surfaces (Manninen et al., 2002; Tucker et al., 2003). It is possible that cattle are strongly focused on the evaluation of the lying surface, rather than stall size, when lying down. Dairy cattle are descendents of plains-dwelling animals, who would rarely have to consider spatial constraints about where to lie down. Stall width affects behavior while animals have contact with the stall surface and partitions (as described previously), but it is unclear if animals evaluate or remember this aspect of the lying space when deciding where to lie down.

Recommendations for stall sizes are normally provided separately for different weight classes of animals (Agriculture Canada, 1990). The experiments reported here were not specifically designed to test the effects of animal size, but, as a secondary aim of experiment 
1 , we examined the effect of animal weight on preferences for lying down in stalls of various sizes. There was no clear relationship between composite size of the freestall used and BW, but the 2 smallest animals tended to use smaller stalls. Further work is likely needed to evaluate how stall usage changes with body size. One approach would be to hold stall size constant and monitor the behavior of a large number of animals varying in size.

Lying time may be important to cows for several reasons. Cows spend a large portion of their time lying, and even a 3-h deprivation of lying is sufficient to cause animals to forego eating in order to lie down (Metz, 1985). Additionally, several physiological changes are associated with reduced lying time in cattle; these include a decrease in circulating levels of growth hormone (Munksgaard and Løvendahl, 1993), a short-term increase in plasma cortisol levels (Ladewig and Smidt, 1989; Fisher et al., 2002), and increased incidence of lameness (Leonard et al., 1994, Singh et al., 1993). More blood circulates to the udder while the animal is lying down compared with when standing (Metcalf et al., 1992). However, no study to date has found differences in milk production clearly linked to duration of lying. Similarly, we found no differences in milk production associated with stall width in experiment 2 . It is possible that the duration and sample size of the experiment were insufficient to detect differences in milk production associated with lower lying times in smaller freestalls, particularly because animals could maintain milk production by metabolizing body stores. However, Rushen et al. (2001) found no difference in milk production when cows were housed in stalls with concrete vs. rubber mat surfaces over a 16-wk experiment, despite a difference between treatments of $1.5 \mathrm{~h} / \mathrm{d}$ in lying time. It is possible that changes in lying time are not associated with milk production, because feed intake, a limiting factor for milk production, may not be affected by the treatments tested. Although we did not measure the amount of feed consumed, other work has shown that deprivation of the opportunity to lie down does not affect feed intake (Ingvartsen et al., 1999). Indeed, Fregonesi and Leaver (2001) have shown that highproducing cows spend more time feeding and less time lying down than low-producing cows, and high milk production is correlated with high DMI (Dado and Allen, 1994).

In addition to longer lying times in wider stalls, the increase in time spent standing with all 4 hooves in the stall may also benefit cows. The wider space between stall partitions provided more room for cows, possibly making it more comfortable for the animals to stand entirely in the stall without contacting the partitions or neck rail. Indeed, in both experiments, the amount of time spent standing with 4 hooves tended to be higher in the wider stalls, although this result was only statistically significant in experiment 2 . Cows may stand in the stall to avoid the relatively uncomfortable standing surface available in the alley, as suggested by Stefanowska et al. (2001). We found marked individual differences in the time cows spent standing this way, perhaps because the increase in stall size was especially important for certain animals. For example, animals with hoof injuries may particularly benefit from the more comfortable standing surface available in the stall, and the lactating cattle in experiment 2 were more likely to be experiencing hoof injuries than the dry animals in experiment 1 (Chaplin et al., 2000). Future experiments should consider the incidence of claw horn lesions and animal size as covariates to better understand the effect of stall size on standing behavior.

Standing with the 2 front hooves in the stall occupied almost $2 \mathrm{~h}$ more time in the smaller stalls relative to the largest stalls in experiment 1. Similarly, in Experiment 2, animals spent 27 min more time standing with front hooves in the stall when tested with the narrowest width relative to the widest width. As with standing entirely in the stall, there was considerable individual variation in this behavior. Some authors have suggested that standing in the stall in this manner may be used to hide from more socially dominant animals (Galindo et al., 2000). However, this was clearly not the case in experiment 1 , because animals were housed individually. An alternative explanation for standing with only the front hooves in the stall may be a reluctance to lie down, perhaps because of cow size, but additional work is required to determine how cow size influences the expression of this behavior. There may also be health consequences associated with excessive standing with only the front hooves in the stall. Two previous studies have indicated that increased standing with the front 2 hooves in the stall predisposed cattle to claw lesions (Colam-Ainsworth et al., 1989; Galindo and Broom, 2000). This may be because increased exposure to moisture is highly correlated with lameness (Fitzgerald et al., 2000), and cattle standing in this position have their back hooves in the relatively moist environment of the alley. In addition, increased exposure to fecal material and concrete surfaces is associated with increased prevalence of hoof diseases (Bergsten and Pettersson, 1992). Thus, in addition to providing a comfortable area to lie down, the design of freestalls should also allow cattle access to a suitable standing surface.

As a potential disadvantage, larger stalls can increase the frequency with which animals defecate and urinate in the stall as opposed to the alley. We found that the widest stalls $(126 \mathrm{~cm})$ in experiment 2 con- 
tained 2.4 times the amount of fecal material compared with stalls measuring $106 \mathrm{~cm}$ and 1.6 times the amount in stalls that were $116 \mathrm{~cm}$ wide. However, readers should be aware that this result is based on very few error degrees of freedom. The increase in fecal material was likely due to animals spending more time lying and standing with all 4 hooves in the stall, positions where fecal material is likely to come in contact with the stall surface. More defecation and moisture from urine in the stall may increase the exposure of teat ends to bacteria and lead to an increased rate of clinical mastitis. It may be possible to reduce the negative effects associated with fecal material and moisture from urine by cleaning stalls and replacing bedding more often. Indeed, improved stall maintenance may be one way to minimize the impact of additional stall soiling associated with wider stalls while still reaping the benefits of larger stalls in terms of longer lying times and less time spent standing with only the front hooves in the stall.

\section{ACKNOWLEDGMENTS}

The authors thank Fay Wan, Sylvia Huang, and Tamiko Thomas for their help in running segments of this study. We also thank members of the University of British Columbia South Campus Research and Teaching Complex, especially Chris Shingara, the staff of the University of British Columbia Dairy Research and Education Center, and the staff and students of University of British Columbia's Animal Welfare Program for their help and cooperation. We thank Jeff Rushen and Brian Thompson for their insightful comments on previous drafts of this document and The William and Charlotte Parks Foundation for Animal Welfare for funding C. B. Tucker while she wrote this manuscript. This research was supported by the National Sciences and Engineering Research Council of Canada through the Industrial Research Chair in Animal Welfare and by contributions from the Dairy Farmers of Canada, the Cattle Industry Development Fund, the British Columbia Dairy Foundation, the British Columbia Society for the Prevention of Cruelty to Animals, members of the British Columbia Veterinary Medical Association, and many other donors listed on our web site at www.agsci.ubc.ca/animalwelfare.

\section{REFERENCES}

Agriculture Canada. 1990. Housing. Pages 9-14 in Recommended Code of Practice for the Care and Handling of Dairy Cattle. Agriculture Canada, Ottawa, Canada.

Bergsten, C., and B. Pettersson. 1992. The cleanliness of cows tied in stalls and the health of their hooves as influenced by the use of electric trainers. Prev. Vet. Med. 13:229-238.
Bickert, W.G. 2000. Freestall design. Pages 205-213 in Proc. Dairy Housing and Equipment Systems: Managing and Planning for Profitability. Nat. Res. Agric. Eng. Serv., Ithaca, NY.

Blom, J. Y., S. P. Konggaard, J. G. Larsson, K. Nielsen, A. Northeved, and P. Solfjeld. 1984. Electronic recording of pressure exerted by cows against structures in free-stall housing. Appl. Anim. Behav. Sci. 13:41-46.

Ceballos, A. 2003. Kinematic analysis of dairy cow lying movements. M.Sc. thesis. Univ. British Columbia, Vancouver, Canada.

Chaplin, S. J., H. E. Ternet, J. E. Offer, D. N. Logue, and C. H. Knight. 2000. A comparison of hoof lesions and behaviour in pregnant and early lactation heifers at housing. Vet. J. 159:147-153.

Colam-Ainsworth, P., G. A. Lunn, R. C. Thomas, and R. G. Eddy. 1989. Behaviour of cows in cubicles and its possible relationship with laminitis in replacement dairy heifers. Vet. Rec.125:573575.

Dado, R. G., and M. S. Allen. 1994. Variation in and relationships among feeding, chewing, and drinking variables for lactating dairy cows. J. Dairy Sci. 77:132-144.

Dumelow, J. 1995. Testing cubicle mats for dairy cows. Agric. Eng. (Winter):17-21.

Faull, W. B., J. W. Hughes, M. J. Clarkson, D. Y. Downham, F. J. Manson, J. B. Merritt, R. D. Murray, W. B. Russell, J. E. Sutherst, and W. R. Ward. 1996. Epidemiology of lameness in dairy cattle: Influence of cubicles and indoor and outdoor walking surfaces. Vet. Rec. 139:130-136.

Fisher, A. D., G. A. Verkerk, C. J. Morrow, and L. R. Matthews. 2002. The effects of feed restriction and lying deprivation on pituitaryadrenal axis regulation in lactating cows. Livest. Prod. Sci. 73:255-263.

Fitzgerald, T., W. Norton, R. Elliott, H. Podlich, and O. L. Svendsen. 2000. The influence of long-term supplementation with biotin on the prevention of lameness in pasture fed dairy cows. J. Dairy Sci. 83:338-344.

Fregonesi, J. A., and J. D. Leaver. 2001. Behaviour, performance, and health indicators of welfare for dairy cows housed in strawyard or cubicle systems. Livest. Prod. Sci. 68:205-216.

Fregonesi, J. A., and J. D. Leaver. 2002. Influence of space allowance and milk yield on behaviour, performance, and health of dairy cows housed in strawyard and cubicle systems. Livest.. Prod. Sci. 78:245-257.

Galindo, F., and D. M. Broom. 2000. The relationships between social behaviour of dairy cows and the occurrence of lameness in three herds. Res. Vet. Sci. 69:75-79.

Galindo, F., D. M. Broom, and P. G. G. Jackson. 2000. A note on possible link between behaviour and the occurrence of lameness in dairy cows. Appl. Anim. Behav. Sci. 67:335-341.

Haley, D. B., J. Rushen, and A. M. de Passillé. 2000. Behavioural indicators of cow comfort: Activity and resting behaviour of dairy cows in two types of housing. Can. J. Anim. Sci . 80:257-263.

Haley, D. B., A. M. de Passillé, and J. Rushen. 2001. Assessing cow comfort: effects of two floor types and two tie stall designs on the behaviour of lactating dairy cows. Appl. Anim. Behav. Sci. 71:105-117.

Ingvartsen, K. L., L. Munksgaard, V. K. M. Nielsen, and L. J. Pedersen. 1999. Responses to repeated deprivation of lying down on feed intake, performance, and blood hormone concentration in growing bulls. Acta Agric. Scand. Sect. A Anim. Sci. 49:260-265.

Irish, W. W., and R. O. Martin. 1983. Design considerations for free stalls. Pages 108-121 in 2nd Proc. Dairy Housing II, Natl. Dairy Housing Conf. Am. Soc. Agric. Eng., St. Joseph, MI.

Ladewig, J., and D. Smidt. 1989. Behavior, episodic secretion of cortisol, and adrenocortical reactivity in bulls subjected to tethering. Horm. Behav. 23:344-360.

Leonard, F. C., J. M. O'Connell, and K. J. O'Farrell. 1994. Effects of different housing conditions on behaviour and foot lesions in Friesian heifers. Vet. Rec. 134:490-494.

Lidfors, L. 1989. The use of getting up and lying down movements in the evaluation of cattle environments. Vet. Res. Commun. 13:307-324. 
McFarland, D. F., and M. J. Gamroth. 1994. Freestall designs with cow comfort in mind. Pages 145-158 in Dairy Systems for the 21st Century, Proc. 3rd Int. Dairy Housing Conf. R. Bucklin (ed.) Am. Soc. Agric. Eng., St. Joseph, MI.

Manninen, E., A. M. de Passillé, J. Rushen, M. Norring, and H. Saloniemi. 2002. Preferences of dairy cows kept in unheated buildings for different kind of cubicle flooring. Appl. Anim. Behav. Sci. 75:281-292.

Maton, A., J. Daelemans, and J. Lambrecht. 1978. Le comportement des vaches laitières en stabulation entravée à litière pailée, en fonction de la largeur du bati. Revue de l'Agric. 31:827-835.

Metcalf, J. A., S. J. Roberts, and J. D. Sutton. 1992. Variations in blood flow to and from the bovine mammary gland measured using transit time ultrasound and dye dilution. Res. Vet. Sci. 53:59-63.

Metz, J. H. M. 1985. The reaction of cows to a short-term deprivation of lying. Appl. Anim. Behav. Sci. 13:301-307.

Mogensen, L., L. H. Nielsen, J. Hindhede, J. T. Sørensen, and C. C. Krohn. 1997. Effect of space allowance in deep bedding systems on resting behaviour, production, and health of dairy heifers. Acta Agric. Scand. Sect. A Anim. Sci. 47:178-186.

Morris, T. R. 1999. Experimental Design and Analysis in Animal Sciences. CAB Int., Wallingford, UK.
Munksgaard, L., and P. Løvendahl. 1993. Effects of social and physical stressors on growth hormone levels in dairy cows. Can. J. Anim. Sci. 73:847-853.

Rushen, J., A. M. de Passillé, D. Haley, E. Manninen, and H. Saloniemi. 2001. Using behavioral indicators and injury scores to assess the effect of stall flooring on cow comfort. Pages 716-723 in Livestock Environment 6. Vol. 2. R. Stowell, R. Bucklin, and R. W. Bottcher (ed.). Am. Soc. Agric. Eng., St. Joseph, MI.

SAS User's Guide: Statistics, Version 6 Edition. 1989. SAS Inst., Inc., Cary, NC.

Singh, S. S., W. R. Ward, K. Lautenbach, J. W. Hughes, and R. D. Murray. 1993. Behaviour of first lactation and adult dairy cows while housed and at pasture and its relationship with sole lesions. Vet. Rec. 133:469-474.

Stefanowska, J., D. Swierstra, C. R. Braam, and M. M. W. B. Hendriks. 2001. Cow behaviour on a new grooved floor in comparison with a slatted floor, taking claw health and floor properties into account. Appl. Anim. Behav. Sci. 71:87-103.

Tucker, C. B., D. M. Weary, and D. Fraser. 2003. Effects of three types of free stall surfaces on preferences and stall usage by dairy cows. J. Dairy Sci. 86:521-529.

Wander, J. F. 1976. Haltungs- und verfahrenstechnisch orientierte Verhaltensforschung. Zuchtungskunde 48:447-459. 